\section{DDU ISSUES ADVICE ON TREATING SLEEP PROBLEMS}

The Dental Defence Union (DDU) has issued advice to dentists on the treatment of sleep problems, in response to a number of recent queries from members on the topic.

The DDU said dentists may be approached more frequently for advice from patients who snore following the screening of the BBC programme 'Goodnight Britain' in November, which featured people being treated for a variety of sleep problems.

Dental professionals are being advised to ensure they are appropriately trained and qualified and follow a recognised treatment protocol. The DDU says most dentists will only have the expertise to treat uncomplicated snoring with an oral appliance and may need to refer patients with more complex problems to their GP.

Rupert Hoppenbrouwers, Head of the DDU, said: 'It is estimated that a third of the UK population snore and while most people will not be seriously troubled by their habit, others may benefit from treatment, which might include the provision of an oral appliance by a dentist.

The DDU advises dentists considering offering patients an oral appliance to help treat snoring to:

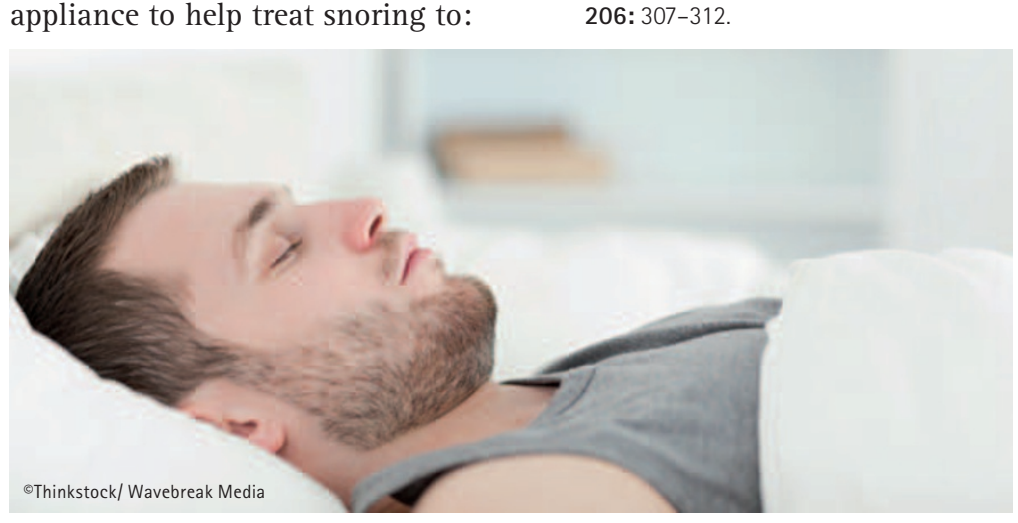

- Consider whether treating sleep

\section{HONOURS, AWARDS, APPOINTMENTS} you can judge whether they may be helped by the fitting of an oral appliance. If you feel the patient needs medical or lifestyle advice, rather than dental treatment, you may need to refer them to their GP disorders falls within your area of competence and expertise and ensure that you have undergone appropriate training

- Follow a recognised protocol; the British Society of Dental Sleep Medicine (BSDSM) has published a treatment protocol $^{1}$

- Ensure patients understand what is involved in the fitting and maintenance of an oral appliance, the risks and benefits, any alternative treatments and the cost

- Keep a record of all discussions in the patient's notes

- Ensure you arrange monitoring and follow-up to see whether the appliance is working

- Inform the DDU if you are planning to carry out this work.

1. Stradling J, Dookun R. Snoring and the role of the GDP: British Society of Dental Sleep Medicine (BSDSM) pre-treatment screening protocol. Br Dent J 2009; 206: 307-312.
Conscious Sedation Masters

In November the MSc in Conscious Sedation in Dentistry was awarded to the first cohort of students at Newcastle University Dr Paul Brady, Dr Alice Harding and Dr David Burgess.

\section{President of ABAOMS}

Professor Graham Ogden was recently elected President of the Association of British Academic and Maxillofacial Surgeons (ABAOMS). ABAOMS is the representative body for academic oral and maxillofacial surgery in the UK. Membership is open to anyone with an interest in research, teaching and clinical practice relevant to the discipline. www.ABAOMS.org.uk

\section{Associate Vice-Provost (Enterprise)}

Professor Andrew Eder has been appointed Associate Vice-Provost (Enterprise) at UCL and Director of CPD and Short Course Development. The position, with a mandate to facilitate growth of this key area across the university, follows Professor Eder's recently completed ten-year term as Director of Education and CPD at the UCL Eastman Dental Institute.

\section{GDC UPDATE}

- A quality assurance and performance management survey of 498 dentists carried out by the GDC has found that $92 \%$ of dentists have carried out CPD in the last year; $75 \%$ have participated in clinical audit; $56 \%$ have been involved in a review of complaints and compliments; $55 \%$ have been involved in personal development planning; and just 29\% have participated in peer review in the last year.

- More than 38,000 dentists have successfully completed their annual registration renewals process with the GDC. Almost 24,000 chose to pay by direct debit. Seven hundred and twenty-three dentists did not re-register and were removed for non-payment, and 737 removed themselves voluntarily or due to retirement.

- The GDC is looking to recruit 65 new Fitness to Practise (FtP) panel members; 15 dentists, 25 DCPs and 25 lay members. Members of the panel sit for around 25 days a year, usually for a minimum of five days at a time. They are paid $€ 353$ a day plus expenses.

\section{PENSION ENTITLEMENTS FOR TRAINING PRACTICES CLARIFIED}

The pension entitlements of training practices in England and Wales have finally been clarified. From April 2013 onwards the training grant is 100\% pensionable; the vocational trainee salary is also pensionable but is not to be included on the annual reconciliation report (ARR); and service costs are not pensionable and must not be included on the ARR.

New pensions guidance has been published by the National Health Service Business Services Authority (NHSBSA).
General confusion on what should be included on an ARR arose following the 2006 contract. David Paul, member of the National Association of Specialist Dental Accountants \&t Lawyers (NASDAL), led the campaign to improve the pension guidance. 